\title{
Young Women with Breast Cancer in Resource-Limited Settings: What We Know and What We Need to Do Better
}

\section{Bertha Alejandra \\ Martinez-Cannon (D) 1,2,* \\ Regina Barragan-Carrillo $\mathbb{I D}^{1,2, *}$ \\ Cynthia Villarreal-Garza $\mathbb{D}^{2,3}$}

'Hematology-Oncology Department, Instituto Nacional de Ciencias Medicas y Nutricion Salvador Zubiran, Mexico City, Mexico; ${ }^{2}$ Joven \& Fuerte: Programa para la Atencion e Investigacion de Mujeres Jovenes con Cancer de Mama en Mexico, Mexico City, Mexico; ${ }^{3}$ Breast Cancer Center, Hospital Zambrano Hellion TecSalud, Tecnologico de Monterrey, San Pedro Garza Garcia, Nuevo Leon, Mexico

*These authors contributed equally to this work
Correspondence: Bertha Alejandra Martinez-Cannon

Hematology-Oncology Department, Instituto Nacional de Ciencias Medicas y Nutricion Salvador Zubiran, Vasco de Quiroga 15, Belisario Dominguez Secc 16, Tlalpan, Mexico City, I4080, Mexico Tel +525554870900

Email amtzcannon@gmail.com

\begin{abstract}
Young women with breast cancer (YWBC) account for a variable proportion of patients diagnosed with breast cancer around the globe, with a higher prevalence in resourcelimited settings than in high-income countries. This group represents a unique population that warrants special attention due to specific biological considerations and age-specific supportive care issues. This review aims to explore existing knowledge regarding YWBC's needs, particularly in resource-restricted settings. To date, scarce information regarding the care of YWBC in resource-constrained countries is available, with most reports describing suboptimal care in terms of survivorship needs. Health care providers should implement actions to improve endocrine treatment adherence, referrals for fertility counseling and preservation, contraceptive use compliance, timely body image and sexual function interventions, comprehensive genetic risk assessments, and early quality of life and psychosocial health interventions. While high costs act as a barrier for optimal care in resource-limited settings, improving patient education represents a promising and cost-effective solution to improve patient care. Future research on developing tailored educational resources for YWBC in resource-limited settings should be considered a priority.
\end{abstract}

Keywords: breast cancer, young women, unmet needs, disparities, resource-limited settings, low- and middle-income countries

\section{Introduction}

Globally, breast cancer (BC) is the most frequently diagnosed malignancy and the leading cause of cancer-related death in women. ${ }^{1}$ In low- to middle-income countries (LMICs), BC is also considered the leading cause of disability among young women. $^{2-4}$ Young women with breast cancer (YWBC), defined as women aged 40 years or less at diagnosis, represent an often underserved population with agespecific needs. ${ }^{5}$ While $\mathrm{BC}$ in young women is considered a relatively rare clinical entity that accounts for $5-7 \%$ of all BC cases in high-income countries (HICs), ${ }^{6}$ LMICs such as Iran $(23 \%),{ }^{7}$ Nigeria $(21 \%),{ }^{8}$ Mexico $(15 \%),{ }^{9}$ India $(15 \%),{ }^{10}$ and Brazil $(11 \%)^{11}$ report a substantially higher proportion of cases diagnosed at a young age. Hence, understanding the particular needs of this population could be vital in optimizing $\mathrm{BC}$ care in resource-limited countries.

YWBC are diagnosed at more advanced stages, with more aggressive pathological features, such as a higher proportion of grade 3, triple-negative, and HER2-positive tumors, and higher rates of recurrence and death compared to their older counterparts. ${ }^{6}$ Additionally, YWBC face not only the threat of a potentially fatal illness and 
burdensome treatment, but also experience an added burden of unique concerns at the peak of their careers, motherhood plans, and family life. ${ }^{5}$ Therefore, attention to age-specific cancer and supportive care issues, including endocrine treatment-related toxicities, fertility counseling and preservation, contraceptive use, body image and sexual function/satisfaction, genetic risk, quality of life (QoL), and psychosocial health, is of utmost importance in this unique population. ${ }^{12}$

Although comprehensive care of YWBC has been found to be suboptimal worldwide, ${ }^{13-15}$ efforts to improve awareness and knowledge among patients and providers about the specific needs of YWBC have been undertaken predominantly in HICs, such as the United States and Canada. $^{12}$ In LMICs, scant resources, limited access to healthcare, and cultural and socioeconomic barriers may further aggravate YWBC's prognosis. ${ }^{16}$ Furthermore, limited data exist on YWBC's special needs, especially in LMICs. ${ }^{2}$ Therefore, the main aim of this review is to explore existing knowledge regarding YWBC's unique needs specifically in resource-limited settings.

\section{Methods}

The authors conducted a comprehensive search using the PubMed database for publications on YWBC in resourcelimited settings. Resource-limited settings were defined as all countries classified as low-income, lower-middleincome, and upper-middle-income economies according to the World Bank Group report, based on its gross national income per capita. ${ }^{17}$ Furthermore, young women were defined as those aged 40 years or younger at $\mathrm{BC}$ diagnosis. Only publications in the English language were considered eligible. The following keywords were searched: breast cancer, young women, special needs, supportive care, limited resource settings, low- and middle-income countries, developing countries, fertility counseling, fertility preservation, contraceptive use, body image, sexual function, sexual satisfaction, genetic risk, quality of life, and psychosocial health. Studies that described YWBC in resource-limited settings, including epidemiological, clinical-pathological, treatment, and supportive care characteristics, were considered for this narrative synthesis.

\section{Endocrine Treatment-Related Concerns}

Although YWBC have a higher proportion of triple-negative and HER2-positive tumors than postmenopausal women, young age by itself is not associated with worse outcomes in these specific subtypes. ${ }^{18}$ Nonetheless, most YWBC will present with hormone receptor (HR)-positive tumors, and patients with this molecular subtype have a higher risk of recurrence and death than their older counterparts. $^{19-22}$ Several theories have been proposed for the unfavorable prognosis in HR-positive tumors in YWBC including treatment failure/resistance, ${ }^{20}$ a higher proportion of luminal B than luminal A tumors, ${ }^{19,23}$ and relatively low rates of adherence to adjuvant endocrine therapy (ET). ${ }^{24,25}$

Current international guidelines recommend adjuvant ET with tamoxifen or an aromatase inhibitor (AI) for at least five and up to 10 years with or without ovarian function suppression (OFS) for premenopausal women with HR-positive BC. ${ }^{26,27}$ Two studies have focused solely on describing ET adherence rates in YWBC in limitedresource settings. Remarkably, both of these studies report high adherence rates to ET in YWBC, contrasting to previous reports from $\mathrm{HICs} .^{28-31}$ The first study to evaluate tamoxifen adherence specifically in YWBC in a resourceconstrained setting was recently published by the "Joven \& Fuerte" program. ${ }^{32}$ In this report, a cross-sectional survey among 141 YWBC receiving adjuvant tamoxifen was conducted at the National Cancer Institute in Mexico City. Adherence to tamoxifen was measured subjectively through self-reported surveys and objectively through the medication possession ratio (MPR). Regarding subjective adherence, 95\% expressed taking tamoxifen regularly, with $70 \%$ reporting not missing any doses in the past 30 days. For objective adherence, $74.8 \%$ of patients had an $\mathrm{MPR} \geq 80 \%$. $^{32}$

Subsequently, the same research group evaluated premenopausal BC patients' adherence to ET and physicians' prescribing practices in three Mexican referral centers (including two public and one private hospitals). Seventy-two percent and $27 \%$ of participants reported complete $(100 \%)$ and acceptable (>80\%) adherence, respectively. Being employed/studying, worrying about long-term ET use, and experiencing ET-related symptoms were associated with incomplete adherence. Treating physicians prescribed guideline-endorsed regimens with tamoxifen or AI plus OFS only in $64 \%$ of patients. However, $88 \%$ of the participants should have received this treatment modality. ${ }^{33}$

Surprisingly, both studies report high adherence rates to $\mathrm{ET}$ in $\mathrm{YWBC}$, contrasting to previous reports from HICs. ${ }^{28-31}$ Causes for the high treatment adherence rates 
described in these two reports may be associated with the fact that patients were being treated in a YWBC specialized program, with increased rates of ET patientprovider discussions before treatment initiation, higher perception of the potential benefits of adjuvant ET, and free of charge medications dispensed in public hospitals. The main reasons associated with patients' low adherence and high discontinuation rates of ET included forgetfulness, adverse effects, and unwillingness to take the medication. ${ }^{32,33}$ As for physicians' suboptimal treatment recommendations with OFS, a possible explanation may be the prevailing limited patient access to gonadotropinreleasing hormone analogs $(\mathrm{GnRHa})$, which are not routinely covered by Mexican public healthcare insurance schemes, and are considered expensive. ${ }^{33}$

Another essential factor that might impact adherence and persistence in this reproductive-aged group is fertility concerns associated with long-term use ET and possibly reduced chances of successful conception. ${ }^{34-36}$ The POSITIVE study is currently investigating the impact of temporary ET interruption to allow pregnancy in premenopausal women with HR-positive early BC who had received 18-30 months of adjuvant ET and wished to interrupt ET for pregnancy, delivery, and breastfeeding, followed by ET resumption to complete the planned duration. Patient accrual has closed, and results on safety of adjuvant ET interruption are currently awaited. Unfortunately, only $6(1.2 \%)$ of the 518 women enrolled in this study, live in a LMIC. ${ }^{35}$

Although young age has been associated as a risk factor for low adherence to adjuvant ET in previous studies in HICs, ${ }^{28,29}$ the scarce available evidence from an upper-middle-income country, Mexico, suggests ET adherence might not be as low as expected in YWBC from LMICs. ${ }^{32,33}$ However, further research concerning this important topic is needed in other limited-constrained settings as YWBC women potentially have longer life expectancies than their older counterparts, and low adherence rates to ET have been associated with worse long-term survival. ${ }^{37}$ Developing setting-adapted strategies to improve physicians' adherence to guideline recommendations and YWBC's adherence to adjuvant ET as well as guaranteeing adequate access to optimal ET are urgently needed in limited-resource settings.

\section{Fertility Counseling and Preservation}

Current BC international guidelines recommend oncofertility counseling to be started as early as possible in the treatment plan of every YWBC, irrespective of subtype and stage of disease, and even if there is no interest in future offspring. A comprehensive fertility counseling is comprised of treatment-related gonadotoxicity assessment, and a discussion on the different strategies available for ovarian function and/or fertility preservation. ${ }^{38}$ Even though oncofertility counseling is an essential component in the management of YWBC, particular barriers in resource-limited settings may be encountered, as attention is mainly directed to cancer diagnosis and treatment, whilst survivorship concerns may be neglected. Such barriers might arise from a lack of engagement from health care providers, limited public coverage for supportive needs heightened by significant socioeconomic gaps, and inequitable distribution of cancer centers and specialists. ${ }^{39}$

In a 2017 Mexican report from a tertiary care center, only $30.6 \%$ of YWBC recalled receiving information from their treating physicians about the infertility risk associated with cancer treatment. ${ }^{40}$ When surveying Mexican physicians on their attitudes and knowledge toward fertility preservation in YWBC, only 58\% claimed they always informed patients about infertility risks, and only $38 \%$ always discussed fertility preservation procedures. Strikingly, $24 \%$ of physicians wrongly considered pregnancy and $20 \%$ GnRHa use during chemotherapy to be detrimental to the prognosis of BC. ${ }^{41}$ Such misconceptions and neglect towards interventions aimed at fertility preservation are not restricted to the Latin American region; a report from East Asia also describes a reduced uptake on fertility preservation strategies due to lack of discussions and referrals to fertility specialists. ${ }^{42}$

Not only physician-related barriers have led to scarce oncofertility referrals in limited-resource settings. In fact, high cost is regarded as one of the most significant barriers for fertility preservation. ${ }^{41,43,44}$ Without insurance coverage, access to fertility preservation strategies is only through out-of-pocket spending, and for a large proportion of BC patients in LMICs, these treatments are unaffordable. $^{39,45}$ This was illustrated in the previously mentioned 2017 Mexican survey, as only 3\% of the surveyed patients considered themselves able to afford extra expenses beyond oncologic treatment. ${ }^{40}$ Furthermore, the short window of time that cancer patients have before starting gonadotoxic cancer treatment further limits fertility preservation referrals, particularly in young Latin American patients with a higher burden of locally advanced disease. ${ }^{46}$ 
Multinational efforts are being made to assess fertility preservation access in resource-limited settings. The Repro-Can-OPEN Study surveyed oncofertility centers from 14 developing countries (Egypt, Tunisia, Brazil, Peru, Panama, Mexico, Colombia, Guatemala, Argentina, Chile, Nigeria, South Africa, Saudi Arabia, and India) on the availability and utilization of different fertility preservation strategies. The most frequent methods for fertility preservation in female patients with $\mathrm{BC}$ identified were gonadal shielding in case of irradiation $(62.5 \%)$, fractionation of chemo- and radiotherapy (62.5\%), and oocyte/ embryo freezing (58.9\% and 55.4\%, respectively). ${ }^{47}$ The systematic development of international efforts among LMICs, such as the Repro-Can-OPEN, represents one of the first steps to enhance quality fertility counseling and access to preservation, but much effort is still needed as these programs were developed mainly in tertiary health care centers. In Mexico, the "Joven \& Fuerte" program has made significant advances to improve access to fertility preservation strategies. In their prospective study on fertility preservation, out of $140 \mathrm{YBCW}$ who desired future offspring before systemic cancer treatment, $38 \%$ could preserve fertility. Among fertility preservation techniques, oocyte/embryo freezing was the most frequently used method (59\%), followed by temporary ovarian suppression with GnRHa during chemotherapy (26\%) or a combination of both strategies $(15 \%){ }^{48}$

\section{Contraceptive Use}

Although BC treatment may have detrimental effects on ovarian function, such as treatment-induced amenorrhea and early menopause, it does not exclude the possibility of pregnancy. ${ }^{49}$ Therefore, contraceptive counseling and adherence are extremely important because reproductiveage $\mathrm{BC}$ patients may have an unintended pregnancy during treatment, restricting the use of some local and systemic therapeutic options, such as radiation therapy, monoclonal antibodies, and ET, and representing added risks for the fetus. ${ }^{50}$ Current studies from HICs show that the use of effective contraceptive methods by YWBC is suboptimal. ${ }^{49,51-53}$ However, information on contraceptive counseling and use in YWBC in LMICs is limited.

In a Turkish qualitative study, premenopausal women with $\mathrm{BC}$ were interviewed to evaluate the information needed and received by those women regarding contraception, early menopause, infertility, fertility preservation, and sexuality. Twenty premenopausal women with $\mathrm{BC}$ reported receiving insufficient counseling on these issues, despite their desire to receive information regarding these issues. Only five of the 18 women who did not want to become pregnant again were using an effective contraceptive method, and only eight had received contraceptive counseling after BC diagnosis. This study demonstrated that premenopausal women with $\mathrm{BC}$ have unmet information needs about contraception and the other related topics. ${ }^{54}$

A cross-sectional survey was conducted regarding contraceptive use and counseling among YWBC who had completed chemotherapy in the previous five years or were currently receiving adjuvant ET and/or trastuzumab at a large tertiary health care facility in Mexico. Of 104 participating women, only $51.1 \%$ and $45.7 \%$ reported using contraception during chemotherapy and adjuvant ET and/or trastuzumab, respectively. Of the 51 patients who were sexually active during chemotherapy, only $29.4 \%$ used an effective contraceptive method. When asked about contraceptive counseling, only $16.7 \%$ recalled being advised by their health care provider about effective strategies. As anticipated, women who received contraception counseling used contraceptives more often than women who were not. ${ }^{55}$

A qualitative study of in-depth interviews among 24 women aged 18-49 years diagnosed with BC at a tertiary hospital in Cape Town, South Africa. Among women using a contraceptive method, the most used strategy after $\mathrm{BC}$ diagnosis was the non-hormonal intrauterine device. Remarkably, all women reported receiving limited information from health care providers about contraceptive use, future fertility planning, impact of cancer treatment on fertility and fertility preservation options. ${ }^{56}$

Thus, only three studies have reported on contraceptive use and counseling in LMICs (Turkey, Mexico, and South Africa) from different continents. These reports demonstrate that YWBC contraception use is low and that women need and are willing to receive information on effective contraceptive options. Notably, these three studies took place in referral cancer centers. Hence, patients in less specialized institutions may have lower use and less counseling on effective contraception. Informing all premenopausal patients about effective contraceptive use during all treatment duration should be an essential component of the supportive care of YWBC.

\section{Body Image and Sexual Function/ Satisfaction}

Sexual function is a fundamental aspect of patients' wellbeing. ${ }^{57} \mathrm{BC}$ treatment modalities can lead to various 
sexual changes among BC survivors. ${ }^{58-60}$ Locoregional treatments, including surgery and radiotherapy, can produce intense emotional distress, cause a detrimental change in body image, and reduce sensitivity in the breasts. Furthermore, systemic treatments, including chemotherapy and ET, can cause premature menopause, decreased libido, dyspareunia, and failure to reach orgasm, leading to reduced sexual activity and satisfaction. ${ }^{59}$

In a qualitative study conducted in Iran, 21 BC survivors under 51 years of age were included for in-depth semi-structured interviews regarding sexual life. The participants experienced changes in sexual function as a result of their $\mathrm{BC}$ diagnosis that led to an unfulfilled sex life. Four main barriers leading to an unfulfilled sexual experience were identified: a) undesirable sexual function, characterized by decreased sexual desire, arousal and satisfaction, less frequent sexual relationships, and perception of diminished sexual attractiveness; b) context-based beliefs, including religious, cultural and family beliefs; c) unmet information and support needs by health care providers; and d) emotional crisis, with feelings of loss of femininity and guilt. ${ }^{57}$

In another qualitative methods study from Nigeria, fifteen women $\leq 45$ years old who underwent mastectomy for $\mathrm{BC}$ were interviewed over a 6-month period. This study identified several major themes on the impact of mastectomy on YWBC's lives. Removal of the breast considerably impacted participants' perception of femininity, making them look physically less like women and more like men. Also, women in this study believed that breasts were foci for sexual arousal. Therefore, they had difficulty becoming sexually aroused and experienced decreased libido after mastectomy, further inflicting them concern about satisfying their husbands. ${ }^{61}$

The "Joven \& Fuerte" group has also reported from a prospective study assessing sexual health using the Female Sexual Function Index (FSFI) and the Sexual Satisfaction Inventory (SSI) at baseline and 6-month follow-up. Mexican YWBC experienced a high percentage of sexual dysfunction, as well as an elevated proportion of low sexual satisfaction at both assessments, with a worse sexual function at follow-up than at baseline. ${ }^{62}$ Similarly, in another cross-sectional study from Iran, 144 premenopausal women with $\mathrm{BC}$ who underwent surgical therapy were assessed using the questionnaires FSFI and Meston's Sexual Satisfaction scale for women. Remarkably, all patients had sexual dysfunction in all dimensions and even lower sexual satisfaction scores with total mastectomy. ${ }^{63}$

More knowledge about the sexual difficulties and adaptation process of young $\mathrm{BC}$ survivors and their partners is needed. The timely identification of women at risk for sexual dysfunction is imperative to provide them with the necessary tools for a fulfilled sexual experience during and after $\mathrm{BC}$ diagnosis and treatment. Tailored interventions to address concerns regarding sexual function and satisfaction need to be developed according to the different cultural and religious backgrounds of YWBC in LMICs.

\section{Genetic Risk}

Among unselected $\mathrm{BC}$ patients, the reported prevalence of germline $B R C A 1 / 2(\mathrm{~g} B R C A)$ pathogenic variants (PVs) is approximately $5 \% .{ }^{64}$ When testing only for YWBC the proportion rises to $12.1 \%,{ }^{65}$ and is even higher when considering only YWBC with triple-negative tumors in whom the prevalence of $\mathrm{g} B R C A$ PVs is reported in up to $23 \%{ }^{66}$ Current National Comprehensive Cancer Network's (NCCN) Guidelines on Hereditary Cancer Testing recommend testing for high penetrance $\mathrm{BC}$ susceptibility genes (BRCA, CDH1, PLB2, PTEN, and TP53) for every woman with a personal history of $\mathrm{BC}$ diagnosed at 45 years or less. Hence, every YWBC should undergo a comprehensive genetic assessment. ${ }^{67}$ Furthermore, BRCA status might also impact treatment-related decisions. The EMBRACA, OlympiAD, and OlympiA phase III trials have shown that $\mathrm{BC}$ patients that carry a $B R C A 1 / 2$ germline mutation might be amenable to treatment with a poly (adenosine diphosphate-ribose) polymerase (PARP) inhibitor in both the advanced and localized settings. ${ }^{68-70}$ Unfortunately, diagnostic genomic tools and genetic counseling services require complex technology and specialized personnel that are not fully accessible in limited-resource settings. ${ }^{71}$

Access to genetic counseling has been reported as an essential area to address among minorities. ${ }^{71}$ Although it has been described that the rate of mutations among breast and ovarian cancer patients does not differ by either ethnicity or race (except for Jewish Ashkenazi), non-Hispanic white females with a family history of breast/ovarian cancer are statistically more likely to be referred to genetic counseling, exemplifying prevailing disparities among underserved populations. ${ }^{72}$ Also, among those patients that were identified as $B R C A$ PVs carriers, non-Hispanic whites were more likely to undergo cancer screening and risk-reducing surgeries compared to patients of other ethnicities. ${ }^{73}$ Furthermore, a qualitative report from the 
US-Mexico border, an underserved area, described that only $3 \%$ of Latina women have knowledge about basic genetic concepts, and this was found to be irrespective of educational status. Among this group, only $1-4 \%$ of women had $B R C A$ testing performed even though most of them declared they would undergo genetic testing within six months if it was offered free of cost. ${ }^{74}$

Barriers to genetic counseling reported from an underdeveloped setting in Europe are mainly related to limited access to healthcare and lack of integrated services. ${ }^{75}$ An important reason for patients to forego genetic testing could be the associated costs. A 2021 review by Grant et al. described that the proportion of patients who declined $\mathrm{BC}$ genetic testing due to cost ranged from $13.6-70.4 \%{ }^{76}$ In a survey of East Asian patients at high risk of developing $\mathrm{BC}$ (ie, personal history of breast/ovarian cancer or a known family member carrier for a $B R C A$ PVs), $71.3 \%$ would not have undergone self-financed genetic screening, emphasizing the importance of sponsored cancer genetic testing services. ${ }^{77}$

One of the main examples of how to address genetic counseling in a limited setting arises from the Genomic Risk Assessment for Cancer Implementation and Sustainment (GRACIAS) intervention in Mexico, which used implementation science methods to develop and deliver low-cost $B R C A$ testing with a $115 B R C A$ panel (HISPANEL) and comprehensive genetic cancer risk assessment across four sites in Mexico. Patient eligibility for genetic assessment included a diagnosis of $\mathrm{BC}$ at a young age and triple-negative BC. Among the four recruiting sites in Mexico, over 1300 women received a comprehensive genetic risk assessment, with $15.6 \%$ identified as carriers of BRCA PVs. Furthermore, a model was adapted to evaluate the proportion of new patients meeting NCCN criteria who participated in genetic assessment among the four sites, reaching $76 \%$ to $90 \%$ of eligible patients. A critical finding from the GRACIAS intervention is the patients' feedback recommending the development of Spanish resources to improve learning. $^{78}$

To this date, one of the main limitations for genetic testing in LMICs has been the lack of readily accessible tools. However, through the recent development of lowcost tests, improved access is expected soon. Nevertheless, the cost of risk-reducing strategies may still represent a barrier to the management of hereditary cancer syndromes. As the cost of genome sequencing is gradually descending, the cost of $\mathrm{BC}$ drugs is rapidly rising. ${ }^{79}$ To address this issue in a high-volume referral center in Latin America, discussions have taken place to find a solution for patient overload. However, only limited actions had taken place at the moment. ${ }^{80}$ Policymakers in Latin America need to carefully balance the benefits and costs of interventions in the rationale of cancer care. $^{71}$ Therefore, efforts should be made to generalize cost-accessible genetic testing and comprehensive counseling for all YWBC, irrespective of their economic background.

\section{QoL and Psychosocial Health}

Quality of life (QoL) has been reported to be worse in YWBC compared to their older counterparts. YWBC experience more significant psychological distress characterized by higher levels of depression and anxiety over the future, particularly regarding motherhood and fear of cancer recurrence. ${ }^{81,82}$ Limited data from LMICs have been published on this topic, and even less information focusing exclusively on YWBC is available.

Results from the pilot phase of the "Joven \& Fuerte" cohort showed that QoL improved significantly two years after BC diagnosis as measured by mean QLQ-C30 global QoL, emotional functioning, pain, and financial difficulty scales. However, physical functioning, nausea/vomiting, and constipation were found to be statistically worse. ${ }^{9}$

Another Mexican study performed one-on-one semistructured interviews at the National Cancer Institute in Mexico City, including 25 YWBC who had survived five or more years after diagnosis. The participating women reported psychological distress, anxiety at the transition to survivorship care, distress when entering the hospital, and explicit requests for psychological care. Notably, the participants expressed that unmet informational needs contributed to their anxiety. ${ }^{83}$

Likewise, in another qualitative Mexican study, 29 YWBC recently diagnosed felt that they were not provided with enough information regarding $\mathrm{BC}$ diagnosis, treatment, and specific side effects affecting fertility, menopause, and sexuality. They reported that such lack of information further exacerbated uncertainty, distress, anxiety, and fear. The participants wished that information was delivered in an empathic and personalized manner, with additional take-home materials to help them remember, understand and/or expand information received during medical appointments. ${ }^{84}$ Similarly, another report from Mexican BC survivors revealed that $97 \%$ YWBC would like to receive more educational information in $\mathrm{BC}$, with a particular interest in the adverse effects of treatment. ${ }^{85}$ 
The development of tailored strategies for YWBC has yielded positive results among Mexican BC patients. After surveying YBCW who are part of the Mexican "Joven \& Fuerte: Program for Young Women with Breast Cancer in Mexico", 97\% reported the program to be useful/very useful, and $82 \%$ believed that the information and support delivered by the program aided to better cope with their illness. Noteworthy, psychological support was identified as the most helpful resource according to participants. ${ }^{86}$

YWBC represent an underserved population, not only regarding specific biologic needs such as fertility preservation and treatment-related sexual dysfunction but also suffer higher levels of anxiety and depression, leading to a worse QoL. Early interventions such as offering psychological counseling and further information on $\mathrm{BC}$ diagnosis and treatment may ameliorate these symptoms and enhance the patients' experience.

\section{Conclusions}

There is scarce information regarding YWBC in limitedresource countries. Further research about the clinical behavior, as well as the supportive care and information needs of YWBC should be a priority, as this population represents a higher proportion of patients in LMICs. Evidence from HICs has shown that dedicated comprehensive programs for YWBC impact patients' cancer and survivorship care and enhance patients' experience. Only a few initiatives have been developed in Latin America, and much effort still needs to be made. Therefore, limitedresource countries could aim to replicate successful specialized programs for YWBC, especially in regions speaking the same language. Furthermore, partnerships between governments and non-profit organizations might also help bridging the resource gap in LMICs.

Many strategies and interventions to enhance clinical care in YWBC are costly and might need resource allocation for their implementation, hindering their adoption in limited economies. However, one high-yield and costeffective intervention that might be useful in every scenario is education. YWBC have externalized on numerous reports their unmet need for information. Hence, every cancer-care team should develop tailored educational resources to optimize patient care.

\section{Acknowledgment}

Martinez-Cannon and Barragan-Carrillo are both to be considered first authors as they contributed equally to this manuscript.

\section{Disclosure}

The authors report no conflicts of interest in this work.

\section{References}

1. Sung H, Ferlay J, Siegel RL, et al. Global cancer statistics 2020: GLOBOCAN estimates of incidence and mortality worldwide for 36 cancers in 185 countries. CA Cancer J Clin. 2021;71(3):209-249. doi:10.3322/caac. 21660

2. Gálvez-Hernández CL, González-Robledo MC, Barragán-Carrillo R, Villarreal-Garza C. Special needs of young women with breast cancer in limited resource settings. Rev Invest Clin. 2017;69(4):210-222.

3. Villarreal-Garza C, Aguila C, Magallanes-Hoyos MC, et al. Breast cancer in young women in Latin America: an unmet, growing burden. Oncologist. 2013;18(Suppl):26-34. doi:10.1634/theoncologist.18-S226

4. Porter P. "Westernizing" women's risks? Breast cancer in lowerincome countries. $N$ Engl $J$ Med. 2008;358(3):213-216. doi:10.1056/NEJMp0708307

5. Paluch-Shimon S, Pagani O, Partridge AH, et al. Second international consensus guidelines for breast cancer in young women (BCY2). Breast. 2016;26:87-99. doi:10.1016/j.breast.2015.12.010

6. Azim HAJ, Partridge AH. Biology of breast cancer in young women. Breast Cancer Res. 2014;16(4):427. doi:10.1186/s13058-014-0427-5

7. Harirchi I, Karbakhsh M, Kashefi A, Momtahen AJ. Breast cancer in Iran: results of a multi-center study. Asian Pac J Cancer Prev. 2004;5 (1):24-27.

8. Adesunkanmi ARK, Lawal OO, Adelusola KA, Durosimi MA. The severity, outcome and challenges of breast cancer in Nigeria. Breast. 2006;15(3):399-409. doi:10.1016/j.breast.2005.06.008

9. Villarreal-Garza C, Platas A, Miaja M, et al. Young women with breast cancer in Mexico: results of the pilot phase of the Joven \& Fuerte prospective cohort. JCO Glob Oncol. 2020;6:395-406. doi:10.1200/JGO.19.00264

10. Deshmukh SP, Mane AD, Zade BP, Sane SP. Breast cancer in young women in India. Ann Oncol. 2012;23:ix101. doi:10.1016/S09237534(20)32826-X

11. Orlandini LF, Antonio MVDN, Espreafico CRJ, et al. Epidemiological analyses reveal a high incidence of breast cancer in young women in Brazil. JCO Glob Oncol. 2021;7:81-88. doi: $10.1200 /$ GO.20.00440

12. Villarreal-Garza C, Martinez-Cannon BA, Platas A, Ramos-Elias P. Specialized programs to support young women with breast cancer. Curr Opin Support Palliat Care. 2015;9(3):308-316. doi:10.1097/ SPC.0000000000000155

13. Partridge AH, Gelber S, Peppercorn J, et al. Web-based survey of fertility issues in young women with breast cancer. J Clin Oncol. 2004;22(20):4174-4183. doi:10.1200/JCO.2004.01.159

14. Fobair P, Stewart SL, Chang S, D’Onofrio C, Banks PJ, Bloom JR. Body image and sexual problems in young women with breast cancer. Psychooncology. 2006;15(7):579-594. doi:10.1002/pon.991

15. Takahashi M. Psychosocial distress among young breast cancer survivors: implications for healthcare providers. Breast Cancer. 2014;21 (6):664-669.

16. Basro S, Apffelstaedt JP. Breast cancer in young women in a limited-resource environment. World J Surg. 2010;34(7):1427-1433. doi:10.1007/s00268-009-0299-5

17. The World Bank. The world by income and region; 2021. Available from: https://datahelpdesk.worldbank.org/knowledgebase/articles/ 906519-world-bank-country-and-lending-groups. Accessed September 22, 2021

18. Villarreal-Garza C, Bargallo-Rocha JE, Soto-perez-de-celis E, et al. Real-world outcomes in young women with breast cancer treated with neoadjuvant chemotherapy. Breast Cancer Res Treat. 2016;157 (2):385-394. doi:10.1007/s10549-016-3811-2 
19. Villarreal-Garza C, Mohar A, Bargallo-Rocha JE, et al. Molecular subtypes and prognosis in young Mexican women with breast cancer. Clin Breast Cancer. 2017;17(3):e95-e102. doi:10.1016/j.clbc.2016.11.007

20. Ahn SH, Son BH, Kim SW, et al. Poor outcome of hormone receptorpositive breast cancer at very young age is due to tamoxifen resistance: nationwide survival data in Korea-a report from the Korean breast cancer society. J Clin Oncol. 2007;25(17):2360-2368. doi:10.1200/JCO.2006.10.3754

21. Azim HA, Michiels S, Bedard PL, et al. Elucidating prognosis and biology of breast cancer arising in young women using gene expression profiling. Clin Cancer Res. 2012;18(5):1341-1351. doi:10.1158/ 1078-0432.CCR-11-2599

22. Villarreal-Garza C, Reynoso-Noveron N, Arce-Salinas C, et al. Abstract P6-08-55: high triple-negative breast cancer prevalence and poor outcome of hormone receptor positive breast cancer among young Mexican women. Cancer Res. 2015;75 (9Supplement):P6-08-55-P6-08-55. doi:10.1158/1538-7445. SABCS14-P6-08-55

23. Tang L-C, Jin X, Yang H-Y, et al. Luminal B subtype: a key factor for the worse prognosis of young breast cancer patients in China. BMC Cancer. 2015;15:201. doi:10.1186/s12885-015-1207-z

24. Hershman DL, Kushi LH, Shao T, et al. Early discontinuation and nonadherence to adjuvant hormonal therapy in a cohort of 8769 early-stage breast cancer patients. $J$ Clin Oncol. 2010;28 (27):4120-4128. doi:10.1200/JCO.2009.25.9655

25. Barron TI, Connolly RM, Bennett K, Feely J, Kennedy MJ. Early discontinuation of tamoxifen: a lesson for oncologists. Cancer. 2007;109(5):832-839. doi:10.1002/cncr.22485

26. Burstein HJ, Temin S, Anderson H, et al. Adjuvant endocrine therapy for women with hormone receptor-positive breast cancer: American society of clinical oncology clinical practice guideline focused update. $J$ Clin Oncol. 2014;32(21):2255-2269. doi:10.1200/JCO.2013.54.2258

27. Paluch-Shimon S, Cardoso F, Partridge AH, et al. ESO-ESMO 4th international consensus guidelines for Breast Cancer in Young Women (BCY4). Ann Oncol. 2020;31(6):674-696. doi:10.1016/j. annonc.2020.03.284

28. Cluze C, Rey D, Huiart L, et al. Adjuvant endocrine therapy with tamoxifen in young women with breast cancer: determinants of interruptions vary over time. Ann Oncol. 2012;23(4):882-890. doi:10.1093/annonc/mdr330

29. Huiart L, Bouhnik AD, Rey D, et al. Early discontinuation of tamoxifen intake in younger women with breast cancer: is it time to rethink the way it is prescribed? Eur J Cancer. 2012;48(13):1939-1946. doi:10.1016/j.ejca.2012.03.004

30. Wassermann J, Gelber SI, Rosenberg SM, et al. Nonadherent behaviors among young women on adjuvant endocrine therapy for breast cancer. Cancer. 2019;125(18):3266-3274. doi:10.1002/cncr.32192

31. Pistilli B, Paci A, Ferreira AR, et al. Serum detection of nonadherence to adjuvant tamoxifen and breast cancer recurrence risk. J Clin Oncol. 2020;38(24):2762-2772. doi:10.1200/JCO.19.01758

32. Martinez-Cannon BA, Castro-Sanchez A, Barragan-Carrillo R, et al. Adherence to adjuvant tamoxifen in Mexican young women with breast cancer. Patient Prefer Adherence. 2021;15:1039-1049. doi:10.2147/PPA.S296747

33. Villarreal-Garza C, Mesa-Chavez F, Ferrigno AS, et al. Adjuvant endocrine therapy for premenopausal women with breast cancer: patient adherence and physician prescribing practices in Mexico. Breast. 2021;59:8-15. doi:10.1016/j.breast.2021.05.013

34. Llarena NC, Estevez SL, Tucker SL, Jeruss JS. Impact of fertility concerns on tamoxifen initiation and persistence. J Natl Cancer Inst. 2015;107(10):djv202. doi:10.1093/jnci/djv202

35. Partridge AH, Niman SM, Ruggeri M, et al. Who are the women who enrolled in the POSITIVE trial: a global study to support young hormone receptor positive breast cancer survivors desiring pregnancy. Breast. 2021;59:327-338. doi:10.1016/j. breast.2021.07.021
36. Sella T, Poorvu PD, Ruddy KJ, et al. Impact of fertility concerns on endocrine therapy decisions in young breast cancer survivors. Cancer. 2021;127(16):2888-2894. doi:10.1002/cncr.33596

37. McCowan C, Shearer J, Donnan PT, et al. Cohort study examining tamoxifen adherence and its relationship to mortality in women with breast cancer. Br J Cancer. 2008;99(11):1763-1768. doi:10.1038/sj. bjc. 6604758

38. Lambertini M, Peccatori FA, Demeestere I, et al. Fertility preservation and post-treatment pregnancies in post-pubertal cancer patients: ESMO clinical practice guidelines†. Ann Oncol. 2020;31 (12):1664-1678. doi:10.1016/j.annonc.2020.09.006

39. Lambertini M, Goldrat O, Barragan-Carrillo R, Vlglietti G, Demeestere I, Villarreal-Garza C. Viable options for fertility preservation in breast cancer patients: a focus on Latin America. Rev Invest Clin. 2017;69(2):103-113. doi:10.24875/RIC.17002179

40. Villarreal-Garza C, Martinez-Cannon BA, Platas A, et al. Fertility concerns among breast cancer patients in Mexico. Breast. 2017;33:71-75. doi:10.1016/j.breast.2017.02.010

41. Villarreal-Garza C, Martinez-Cannon BA, Barragan-Carrillo R, et al. Physicians' attitudes, knowledge, and perceived barriers toward fertility preservation in young breast cancer patients in a developing country. Rev Invest Clin. 2020;73(3):347-353.

42. Kim J, Kim SK, Hwang KJ, Kim SH. Fertility preservation during cancer treatment: the Korean society for fertility preservation clinical guidelines. Clin Exp Reprod Med. 2017;44(4):171. doi:10.5653/ cerm.2017.44.4.171

43. Dyer KE, Quinn GP. Cancer and fertility preservation in Puerto Rico: a qualitative study of healthcare provider perceptions. Support Care Cancer. 2016;24(8):3353-3360. doi:10.1007/s00520-016-3166-6

44. Khan SZ, Garza CV, Sirohi B, et al. 8P Knowledge, practice and attitudes of physicians in low- and middle-income countries (LMIC) on fertility and pregnancy-related issues in young breast cancer patients. Ann Oncol. 2020;31:S1245. doi:10.1016/j. annonc.2020.10.028

45. Panagiotopoulou N, Ghuman N, Sandher R, Herbert M, Stewart JA. Barriers and facilitators towards fertility preservation care for cancer patients: a meta-synthesis. Eur J Cancer Care. 2018;27(1):e12428. doi:10.1111/ecc. 12428

46. Pinto JA, Pinillos L, Villarreal-Garza C, et al. Barriers in Latin America for the management of locally advanced breast cancer. Ecancermedicalscience. 2019;13:897. doi:10.3332/ecancer.2019.897

47. Salama M, Laronda MM, Laura ER, et al. Installing oncofertility programs for common cancers in optimum resource settings (Repro-Can-OPEN Study Part II): a committee opinion. J Assist Reprod Genet. 2021;38(1):163-176. doi:10.1007/s10815-02002012-0

48. Villarreal-Garza C, Mesa-Chavez F, Plata de la Mora A, et al. Prospective Study of fertility preservation in young women with breast cancer in Mexico. J Natl Compr Canc Netw. 2021:1-8. doi:10.6004/jnccn.2020.7692

49. Guth U, Huang DJ, Bitzer J, Moffat R. Unintended pregnancy during the first year after breast cancer diagnosis. Eur J Contracept Reprod Health Care. 2016;21(4):290-294. doi:10.1080/13625187.2016.1180678

50. Durrani S, Akbar S, Heena H. Breast cancer during pregnancy. Cureus. 2018;10(7):e2941. doi:10.7759/cureus.2941

51. Maslow B-SL, Morse CB, Schanne A, Loren A, Domchek SM, Gracia CR. Contraceptive use and the role of contraceptive counseling in reproductive-aged women with cancer. Contraception. 2014;90 (1):79-85. doi:10.1016/j.contraception.2014.03.002

52. Johansen SL, Lerma K, Shaw KA. Contraceptive counseling in reproductive-aged women treated for breast cancer at a tertiary care institution: a retrospective analysis. Contraception. 2017;96 (4):248-253. doi:10.1016/j.contraception.2017.06.004

53. Cook-Andersen H, Komrokian S, DeMichele A, Su HI. Breast cancer patients have lower rates of contraception use. Fertil Steril. 2011;96 (3):S201-S202. doi:10.1016/j.fertnstert.2011.07.781 
54. Karaöz B, Aksu H, Küçük M. A qualitative study of the information needs of premenopausal women with breast cancer in terms of contraception, sexuality, early menopause, and fertility. Int J Gynaecol Obstet. 2010;109(2):118-120. doi:10.1016/j.ijgo.2009.11.027

55. Castro-Sanchez A, Martinez-Cannon BA, Platas A, et al. Suboptimal use of effective contraceptive methods in young Mexican women with breast cancer. J Glob Oncol. 2018;4:1-7. doi:10.1200/ JGO.18.00064

56. Harries J, Constant D, Cairncross L, Moodley J. Contraceptive needs and fertility intentions of women with breast cancer in Cape Town, South Africa: a qualitative study. BMC Women's Health. 2020;20 (1):224. doi:10.1186/s12905-020-01094-3

57. Maleki M, Mardani A, Ghafourifard M, Vaismoradi M. Qualitative exploration of sexual life among breast cancer survivors at reproductive age. BMC Women's Health. 2021;21(1):56. doi:10.1186/s12905021-01212-9

58. Gilbert E, Ussher JM, Perz J. Sexuality after breast cancer: a review. Maturitas. 2010;66(4):397-407. doi:10.1016/j.maturitas.2010.03.027

59. Ghizzani A, Bruni S, Luisi S. The sex life of women surviving breast cancer. Gynecol Endocrinol. 2018;34(10):821-825. doi:10.1080/ 09513590.2018.1467401

60. Ussher JM, Perz J, Gilbert E. Information needs associated with changes to sexual well-being after breast cancer. $J A d v$ Nurs. 2013;69(2):327-337. doi:10.1111/j.1365-2648.2012.06010.x

61. Olasehinde O, Arije O, Wuraola FO, et al. Life without a breast: exploring the experiences of young Nigerian women after mastectomy for breast cancer. J Glob Oncol. 2019;5:1-6. doi:10.1200/ JGO. 18.00248

62. Villarreal-Garza CM, Platas A, Castro-Sanchez A, et al. Sexual function and satisfaction in Mexican young women undergoing breast cancer treatment. J Clin Oncol. 2017;35(15_suppl):e21714-e21714. doi:10.1200/JCO.2017.35.15_suppl.e21714

63. Fouladi N, Feizi I, Nadermohammadi M, Mehrara E, Adldoosti R, Alimohammadi S. The predictors of sexual satisfaction among Iranian women with breast cancer. Asian Pac J Cancer Prev. 2021;22(2):391-396. doi:10.31557/APJCP.2021.22.2.391

64. Armstrong N, Ryder S, Forbes C, Ross J, Quek RG. A systematic review of the international prevalence of BRCA mutation in breast cancer. Clin Epidemiol. 2019;11:543-561. doi:10.2147/CLEP. S206949

65. Rosenberg SM, Ruddy KJ, Tamimi RM, et al. BRCA1 and BRCA2 mutation testing in young women with breast cancer. JAMA Oncol. 2016;2(6):730. doi:10.1001/jamaoncol.2015.5941

66. Villarreal-Garza C, Weitzel JN, Llacuachaqui M, et al. The prevalence of BRCA1 and BRCA2 mutations among young Mexican women with triple-negative breast cancer. Breast Cancer Res Treat. 2015;150(2):389-394. doi:10.1007/s10549-015-3312-8

67. Daly MB, Pal T, Berry MP, et al. Genetic/familial high-risk assessment: breast, ovarian, and pancreatic, version 2.2021, NCCN clinical practice guidelines in oncology. $J$ Natl Compr Canc Netw. 2021;19 (1):77-102. doi:10.6004/jncen.2021.0001

68. Litton JK, Rugo HS, Ettl J, et al. Talazoparib in patients with advanced breast cancer and a germline BRCA mutation. $N$ Engl $J$ Med. 2018;379(8):753-763. doi:10.1056/NEJMoa1802905

69. Robson ME, Tung N, Conte P, et al. OlympiAD final overall survival and tolerability results: olaparib versus chemotherapy treatment of physician's choice in patients with a germline BRCA mutation and HER2-negative metastatic breast cancer. Ann Oncol. 2019;30 (4):558-566. doi:10.1093/annonc/mdz012

70. Tutt ANJ, Garber JE, Kaufman B, et al. Adjuvant olaparib for patients with BRCA1 - or BRCA2 -mutated breast cancer. $N$ Engl J Med. 2021;384(25):2394-2405. doi:10.1056/NEJMoa2105215
71. Chavarri-Guerra Y, Blazer KR, Weitzel JN. Genetic cancer risk assessment for breast cancer in Latin America. Rev Invest Clin. 2017;69(2):94-102. doi:10.24875/RIC.17002195

72. Cruz-Correa M, Pérez-Mayoral J, Dutil J, et al. Clinical cancer genetics disparities among latinos. J Genet Couns. 2017;26 (3):379-386. doi:10.1007/s10897-016-0051-x

73. Chapman-Davis E, Zhou ZN, Fields JC, et al. Racial and ethnic disparities in genetic testing at a hereditary breast and ovarian cancer center. J Gen Intern Med. 2021;36(1):35-42. doi:10.1007/s11606020-06064-x

74. Chalela P, Pagán JA, Su D, Muñoz E, Ramirez AG. Breast cancer genetic testing awareness, attitudes and intentions of latinas living along the US-Mexico border: a Qualitative Study. J Community Med Health Educ. 2012;2. doi:10.4172/2161-0711.1000152

75. Bellaiche MMJ, Fan W, Walbert HJ, et al. Disparity in access to oncology precision care: a geospatial analysis of driving distances to genetic counselors in the U.S. Front Oncol. 2021;11:689927. doi:10.3389/fonc.2021.689927

76. Grant P, Langlois S, Lynd LD, Austin JC, Elliott AM. Out-of-pocket and private pay in clinical genetic testing: a scoping review. Clin Genet. 2021;100(5):504-521. doi:10.1111/cge.14006

77. Chu AT-W, Tse DM-S, Suen DTK, Kwong A. Baseline knowledge and receptiveness to genetic testing for hereditary breast and ovarian cancer syndromes in Chinese high-risk females. J Community Genet. 2021;12(3):431-438. doi:10.1007/s12687-021-00518-3

78. Blazer KR, Chavarri-Guerra Y, Villarreal Garza C, et al. Development and pilot implementation of the Genomic Risk Assessment for Cancer Implementation and Sustainment (GRACIAS) intervention in Mexico. JCO Glob Oncol. 2021;7 (7):992-1002. doi:10.1200/GO.20.00587

79. Kantarjian H, Steensma D, Rius Sanjuan J, Elshaug A, Light D. High cancer drug prices in the United States: reasons and proposed solutions. J Oncol Pract. 2014;10(4):e208-e211. doi:10.1200/ JOP.2013.001351

80. Villarreal-Garza C. Abstract IA23: steps to address the profound disparity in access to genetic cancer risk assessment in Mexico: documenting hereditary breast and ovarian cancer and the beginning of a prevention program. In: Behavioral and Social Science. American Association for Cancer Research; 2015:IA23-IA23. doi:10.1158/1538-7755.DISP14-IA23

81. Howard-Anderson J, Ganz PA, Bower JE, Stanton AL. Quality of life, fertility concerns, and behavioral health outcomes in younger breast cancer survivors: a systematic review. $J$ Natl Cancer Inst. 2012;104(5):386-405. doi:10.1093/jnci/djr541

82. Yfantis A, Intas G, Tolia M, et al. Health-related quality of life of young women with breast cancer. Review of the literature. $J$ BUON. 2018;23(1):1-6.

83. Hubbeling HG, Rosenberg SM, González-Robledo MC, et al. Psychosocial needs of young breast cancer survivors in Mexico City, Mexico. Gripsrud BH, ed. PLoS One. 2018;13(5):e0197931. doi:10.1371/journal.pone.0197931

84. Villarreal-Garza C, López-Martínez EA, Martínez-Cannon BA, et al. Medical and information needs among young women with breast cancer in Mexico. Eur J Cancer Care. 2019;28(4). doi:10.1111/ ecc. 13040

85. Villarreal-Garza C, Platas A, Martinez-Cannon BA, et al. Information needs and internet use of breast cancer survivors in Mexico. Breast $J$. 2017;23(3):373-375. doi:10.1111/tbj.12747

86. Villarreal-Garza C, Platas A, Miaja M, et al. Patients' satisfaction with a supportive care program for young breast cancer patients in Mexico: Joven \& Fuerte supports patients' needs and eases their illness process. Support Care Cancer. 2020;28(10):4943-4951. doi:10.1007/s00520-020-05334-y 


\section{Publish your work in this journal}

Breast Cancer - Targets and Therapy is an international, peer-reviewed open access journal focusing on breast cancer research, identification of therapeutic targets and the optimal use of preventative and integrated treatment interventions to achieve improved outcomes, enhanced survival and quality of life for the cancer patient.
The manuscript management system is completely online and includes a very quick and fair peer-review system, which is all easy to use. Visit $\mathrm{http}: / /$ www.dovepress.com/testimonials.php to read real quotes from published authors.

Submit your manuscript here: https://www.dovepress.com/breast-cancer-targets-and-therapy-journal 